\title{
Legal Dilemma and Way Out in the Environment of "Big Data Discriminatory Pricing"
}

\author{
Zixi Liu ${ }^{1}$, Wendai He${ }^{2}$, Weicong $\mathrm{Chen}^{3}$, Zhaorui Zhu', Yuan Zhous,* \\ ${ }^{1}$ Institute of Information Engineering, Sichuan Agricultural University, Sichuan, China \\ ${ }^{2}$ Institute of Management, Sichuan Agricultural University, Sichuan, China \\ ${ }^{3}$ Institute of Law, Peking University, Beijing, China \\ ${ }^{4}$ Institute of Law, Zhongnan University of Economics and Law, Wuhan, China \\ ${ }^{5}$ Institute of Law, Sichuan Agricultural University, Sichuan, China \\ *Corresponding author. Email:2225153328@qq.com
}

\begin{abstract}
In recent years, the rapid development of big data technology has brought convenience to the lives of citizens, but also brought some hidden dangers. The phenomenon of "big data discriminatory pricing(BDDP)" is becoming more and more common, not only causing damage to the market and economy, but also impacting traditional laws and regulations. In response to this phenomenon, the author firstly points out the shortcomings of the current legislation from the three levels of price discrimination, consumer rights protection and personal information protection; then the author points out the current relief system in society, the applicability of the law, and the supervision of the platform. Starting from the direction, the author analyzes the plight of current laws and regulations. Finally, from three perspectives, the author puts forward new governance suggestions to effectively protect the legitimate rights and interests of citizens.
\end{abstract}

Keywords:"big data discriminatory pricing(BDDP)", law, price discrimination, consumer rights protection, personal information protection

\section{INTRODUCTION}

In recent years, the platform economy in the field of e-commerce in China has developed rapidly. Many network platforms have risen rapidly and have become a force that cannot be ignored in economic life, but they have also brought new drawbacks. "BDDP" has been a controversial topic in recent years. The platform accurately derives user preferences and consumption habits through algorithmic analysis of massive data, and makes differential pricing based on these data. This phenomenon has gradually caused dissatisfaction among consumers, and even led to a crisis of trust among consumers on the platform [1].

Domestic scholars have also begun to think about the origin of this kind of phenomenon, and provide solutions from different perspectives such as law, economy, and algorithms. Zou [2] believes that this kind of phenomenon leads to severe competition among operators, which makes consumers in a weak position and the market is destroyed, and on this basis, they discuss legal defects. Zhan [3] combined with economic analysis to conclude that although price discrimination in the context of big data violates consumers' fair trading rights, it objectively optimizes transaction efficiency. $\mathrm{Wu}[4]$ cut from the perspective of personal information protection and discussed information-related issues such as legal collection and the necessity of the scope of information collection. Wang [5] learned from the decentralized legislation in the United States and suggested the establishment of an Internet court to further regulate this type of phenomenon. Sun [6] believes that the relevant laws and regulations will be adjusted, refined, and kept the bottom line clauses in order to regulate this phenomenon. Shen [7] gave suggestions from the perspective of algorithms, using examples to demonstrate that the development of algorithms may harm consumer rights. Zeng [8] analyzed the theoretical concept of "BDDP". After introducing the principle and analyzing the status, he gave a framework for the combination of anti-monopoly law and other laws.

Although the above scholars approached the issue of 
differential pricing in the context of big data from different directions, they also gave pertinent suggestions, but "BDDP" is a complex phenomenon that involves many social aspects. From a certain perspective, scholars cannot solve the whole phenomenon well. In response to this problem, this article explores the root causes of the phenomenon of "BDDP" from a different perspective. The author proposes a reasonable governance path based on the actual situation, hoping to effectively promote the improvement of social ills.

\section{THE DEVELOPMENT OF "BDDP"}

In recent years, this problem has continued to ferment at home and abroad. Starting in March 2018, someone booked a hotel on a travel website at a price of between 380 and 400 yuan, but a friend who did not often book a hotel found a room price of 300 yuan. This kind of phenomenon also occurs on the Didi platform. Through comparative experiments, it is found that using the same application software to call a taxi costs more than those who rarely take taxis. This kind of phenomenon is becoming more and more common in foreign countries. In 2000, Amazon users found that the price of DVD was lower than before after removing the cookie; in 2012, the Wall Street Journal reported that the Stamples website would charge different fees based on the residence of registered users. In 2018, many foreign media claimed that Facebook admitted that Cambridge Analytica, a data analysis company, illegally obtained 50 million Facebook user information and helped Trump win the 2016 U.S presidential election. Therefore, the advent of the information age has gradually increased the frequency of "BDDP", and it has also brought major challenges to the protection of citizens' rights.

\section{INSUFFICIENCY OF CURRENT LEGISLATION}

The author believes that the reason for the phenomenon of "BDDP" is caused by the conflict of laws from different angles, which can be divided into three angles: price discrimination, consumer rights protection and personal information protection.

The "Anti-Monopoly Law" makes the following provisions on price discrimination. It refers to the behavior of a business operator with a dominant market position in the transaction price of the transaction counterparty with the same conditions without a legitimate reason. However, in general, there is no clear explanation for what is "same conditions", what is "differential treatment in price", and what is "justified reason". In practice, the ambiguity of this kind of regulation has brought a lot obstacle to the determination of price discrimination.
Regarding the provisions on the differential pricing of business operators, Article 22 of China's "Consumer Rights Protection Law" imposes an obligation to "mark prices" for business operators, and Article 55, paragraph 1, stipulates that Punitive compensation measures for fraudulent acts. Some people believe that the successful implementation of the "BDDP" behavior is that the platform takes advantage of the information asymmetry between it and consumers to adopt differential pricing. This behavior also damages consumers' right to know, but from the point of view of the provisions, the consumer's right to know does not include the right to understand the operator's pricing strategy. Therefore, if the " BDDP" behavior is regulated from the perspective of consumer protection, only some principled regulations can be applied. However, since the law does not provide for a clear form of liability, in practice, it is difficult for consumers to obtain compensation from the operators for damages. China's relevant legislation on users' personal information is relatively sound. Article 111 of the General Principles of the Civil Law swearly stipulates the personal information protection system for natural persons. Both the Consumer Rights Protection Law and the Cyber Security Law stipulate consumer personal information. However, these laws and regulations involve the boundary problem of the use of personal data and personal information under different incidents. The personal information is also different under different events. Since the algorithm is not an object in the real state, the algorithm mechanism is only a series of codes in the final analysis. In the case of "BDDP", users cannot accurately enumerate the degree of infringement by operators on citizens' personal information.

\section{THE LEGAL DILEMMA OF "BDDP"}

\subsection{The current law is not applicable}

After sorting out the current laws and regulations in China, we can draw the conclusion: Although many laws and regulations in China make relevant provisions, these provisions are all produced under the traditional market regulation system and cannot reflect the development and differences of big data in the Internet era. Because of the characteristics of pricing, it is also difficult to directly quote these provisions to restrict "BDDP". The behavior of "BDDP" originated in the Internet era, and its harm is manifested in the fact that e-commerce platform operators rely on their absolute superiority in information control to differentiate prices for consumers, which damages consumers' right to fair transactions. When users suffer from such phenomena and damage their rights and interests, the "Price Law", "Consumer Protection Law" and other laws and regulations lack applicability and are difficult to play a substantive role. 


\subsection{Insufficient supervision of platforms by law}

At present, research on the supervision of platform "price algorithm" in various countries in the world is still in its infancy, and there is no clear conclusion on the possible impact of platform "price algorithm" and the regulatory countermeasures that should be adopted. As far as China is concerned, the current level of supervision of platforms by administrative agencies is relatively low, the law does not specify a specific supervisory body, and the supervisory model is relatively backward. E-commerce platform behavior also lacks a dedicated supervisory body. For example, when ordering a hotel, if there is a phenomenon of "BDDP", the behavior may touch the supervision responsibilities of the tourism management department, the Ministry of Industry and Information Technology, the Cyberspace Administration of China and other related departments, and the overlap of supervision responsibilities between different agencies is inevitable. There are many cases of mutual evasion of supervisory responsibilities among institutions, resulting in a great reduction in supervisory efficiency.

\subsection{GOVERNANCE PATHS FROM DIFFERENT PERSPECTIVES}

\subsection{Expand the scope of consumers' right to know}

The current laws and regulations lack clear provisions on whether the "BDDP" behavior is illegal. The current laws and regulations also have certain lagging and weak applicability problems. Platform operators can accurately analyze consumers through the collected personal information and data of consumers. With the powerful ability to change prices, the platform can even adjust commodity prices in real time and make differential pricing for different consumers. This situation conforms to the literal meaning of "clearly marked price" in form, but actually violates the "clearly marked price" requirement. The author suggests that the scope of consumers' right to know should be broadened, and platform operators should be required to inform consumers of their collection and analysis of user personal information and pricing models in a reasonable manner. After clarifying the consumer's right to know the platform's such pricing methods, the platform constitutes price fraud if the platform should inform but not the consumer. Consumers can request damages from the platform on this basis to further protect the right to know.

\subsection{Improve current laws and regulations}

First of all, in view of the inadequacy of relevant provisions on price discrimination in the law, the author believes that it should be clear that such behaviors by operators of differential pricing of consumers are price discrimination. Secondly, there is a conflict between the "Anti-Monopoly Law" and the "Price Law" on the connotation of price discrimination. The author believes that the specific connotation of price discrimination should be clarified, and the provisions between the two laws should be coordinated to maintain the elements of price discrimination. Finally, China's "E-commerce Law", although it covers a wide range of content, lacks reference in the formulation process, there are many provisions that do not have strong operability. The author proposes to add provisions prohibiting "BDDP" behavior in relevant legal provisions or judicial interpretations in the future.

\subsection{Increasing the supervision of the platform}

Regulatory authorities should strengthen the supervision of platform big data behaviors, use technical means to monitor and warn the platform's big data behaviors, and use big data technology to counteract "BDDP" behavior when necessary, and use big data technology to sort out Merchant's transaction information, screen out suspicious transaction information and severely punish "BDDP" behavior. When appropriate, external sanctions and restraint mechanisms can be introduced to improve the efficiency and intensity of law enforcement. Only in this way can an honest, fair, and transparent trading environment be established, and big data can be prevented from becoming a platform for profit-making tools, and consumers can be hunted by advanced technologies. At the same time, the author suggest that we can learn from the experience of the European Union and set up special data protection officers in e-commerce platform companies to monitor their data processing behavior in real time. The European Union provides for the establishment of data protection officers in companies that handle personal information on a large scale to facilitate real-time evaluation of companies' handling of personal information and data, and timely adjustment of management and technical measures and data protection strategies based on possible risks. The data protection officer should serve as a relatively independent supervisory agency within the platform company. The staff should be individuals who have extensive professional knowledge and have no interest in the platform company. They can be appointed by a third-party organization and are responsible to the supervisory department at the same time.

\section{CONCLUSION}

China's current research on the "BDDP" behavior of e-commerce platform operators is insufficient, and there is also a lack of specific regulations in relevant legislation. This article defines the behavior of "BDDP" on the basis of scholars' research, and clarifies that 
China has problems such as lagging legislation, weak protection of personal data information, inadequate platform supervision, and imperfect consumer relief system. Regarding regulatory issues, the author puts forward relevant suggestions to clarify the illegal identification standards of "BDDP" in relevant legislation, and strengthen the substantive protection of consumer personal information and improve the platform's supervision system.

\section{REFERENCES}

[1]JianKai Liao. The Dilemma and Way Out of Legal Regulation of "big data discriminatory pricing" From Consumer's Rights Protection to Operator's Algorithmic Power Governance[J].Journal of Southwest University of Political Science and Law,2020,22(01):70-82.

[2]KaiLiang Zou,MingJia Liu. Legal regulation of price discrimination in the context of big data[J].Journal of Anyang Institute of Technology,2018,17(01):16-19.

[3]JingFu Zhan,XianLin Wang. A First Look at Big Data Issues from an Antitrust Perspective[J].Price:Theory \& Practice, 2018(09):37-42.

[4]WeiMing $\mathrm{Wu}, \mathrm{Yu}$ Zhang. Research on the legal regulation of financial user profiling[J].FinTech Time,2018(09):13-19.

[5]HengRui Wang. Protection of Consumers' Fair Trade Rights in the Context of Big Data Killing[J].Big Data Time,2018(11):20-24.

[6]ShanWei Sun. Legal Regulation of Price Fraud in the Context of Big Data - Taking big data discriminatory pricing as an Example[J].Northern Economy and Trade,2018(07):51-52.

[7]LiangLiang Shen. The Application of Algorithms in Market Competition and Legal Difficulties - From big data discriminatory pricing[J].Journal of Taiyuan University(Social Science Edition),2019,20(03):26-31.

[8]Xiong Zeng. Competition Law Regulation of "big data discriminatory pricing" - The Concept of Personalized Pricing $[\mathrm{J}]$.China Internet,2019(09):26-32. 